\title{
Renal Rupture Associated with a Poorly Differentiated Follicular Thyroid Carcinoma Metastasizing to the Thigh Muscle, Lung and Kidney
}

\author{
Hiroshi IwaI, Yasuhiro OHnO, Hiroyuki ITO, Tomomi KiYOKAWA and Norihiko AOKI
}

\begin{abstract}
A 76-year-old woman with a history of total thyroidectomy for a thyroid carcinoma at the age of 63 was admitted to our hospital for the treatment of a renal rupture induced by a tumor of about $3 \mathrm{~cm}$ in diameter. High levels of blood thyroglobulin $(\mathrm{Tg}>1,000 \mathrm{ng} / \mathrm{ml})$ led us to suspect a recurrence of thyroid carcinoma. Strong accumulation in whole-body ${ }^{123} \mathrm{I}$ and ${ }^{201} \mathrm{Tl}$ scintigraphy scans after the nephrectomy revealed tumors in the right lung and left thigh muscle measuring $5 \mathrm{~cm}$ and $9 \mathrm{~cm}$ in diameter, respectively. The tumors of the kidney and thigh muscle were pathologically diagnosed as poorly differentiated follicular thyroid carcinoma, and the lung tumor was also suggested to be a metastasis of the thyroid carcinoma based on the scintigraphy findings. We report this rare case of follicular thyroid carcinoma associated with metastases to the thigh muscle and kidney leading to a rupture 13 years after a total thyroidectomy. Care should be taken to determine whether unknown tumors are thyroid carcinoma metastases.

(Internal Medicine 44: 848-852, 2005)
\end{abstract}

Key words: follicular thyroid carcinoma, renal rupture, distant metastases, p53 antibody

\section{Introduction}

Thyroid carcinoma has a good prognosis and low mortality, with a 10-year survival of over $90 \%$ (1). Papillary and follicular thyroid carcinomas metastasize in $9 \%$ and $25 \%$ of all cases, respectively (2). The major sites of the distant metastases of thyroid carcinomas are the lungs and bones, accounting for about $50 \%$ and $18 \%$ of the distant metastases, respectively (2-4). The minor sites include the brain, liver, skin, pleura, kidneys, pericardium, diaphragma, etc. $(2,3)$. To the best of our knowledge, there have no reported cases of thyroid carcinoma associated with metastases to the thigh muscle, and none of the earlier metastases to the kidney have been associated with renal rupture.

Here, we report a rare case of thyroid carcinoma associated with metastases to the thigh muscle and possibly to the lung and kidney 13 years after a total thyroidectomy.

\section{Case Report}

A 76-year-old woman complained of macrohematuria and right flank pain. An abdominal ultrasonography (US) showed a hypervascular and heterogeneous tumor of about 3 $\mathrm{cm}$ in diameter in the right kidney. She was admitted to our hospital for examination and treatment of the renal tumor on June 27, 2001.

Thirteen years earlier, at the age of 63 , the patient had undergone a total thyroidectomy for a follicular thyroid carcinoma (T3 N0 M0, stage II). After the total thyroidectomy she received a hormone replacement therapy at a daily dose of $50 \mu \mathrm{g}$ of levothyroxine in combination with $1 \mu \mathrm{g}$ of alphacalcidol and $3 \mathrm{~g}$ of calcium lactate. However, she failed to closely adhere to the regimen prescribed. At the age of 69 , a chest X-ray taken during a routine medical check-up revealed a brush-like abnormal shadow in the right lung field $\left(\mathrm{S}_{4}\right)$. The findings of a transbronchial lung biopsy (TBLB) showed fibrosis but no malignancy. Her blood thyroglobulin (Tg) level was at less than $5 \mathrm{ng} / \mathrm{ml}$ at that time. Over the next seven years she received few medical check-ups. Her family history included a hypertensive father and a mother with cardiac valvular disease.

Her physical examinations on admission were as follows: her height was $143.2 \mathrm{~cm}$, body weight $47.6 \mathrm{~kg}$, body temperature $35.9{ }^{\circ} \mathrm{C}$, blood pressure $140 / 70 \mathrm{mmHg}$, and pulse

From the Department of Endocrinology, Metabolism and Diabetes, Kinki University School of Medicine, Osaka

Received for publication April 28, 2004; Accepted for publication April 22, 2005

Reprint requests should be addressed to Dr. Hiroshi Iwai, the Department of Endocrinology, Metabolism and Diabetes, Kinki University School of Medicine, 377-2 Ohno-Higashi, Osaka-Sayama, Osaka 589-8511 
Distant Metastases in Thyroid Carcinoma

Table 1. Laboratory Data on Admission

\begin{tabular}{|c|c|c|c|c|c|c|}
\hline \multicolumn{2}{|c|}{ Blood cell count } & $\mathrm{Na}$ & $142 \mathrm{mEq} / \mathrm{l}$ & $\mathrm{Fe}$ & $52 \mu \mathrm{g} / \mathrm{dl}$ & $(70-180)^{*}$ \\
\hline WBC & $5,500 / \mu 1$ & $\mathrm{~K}$ & $4.3 \mathrm{mEq} / \mathrm{l}$ & TIBC & $237 \mu \mathrm{g} / \mathrm{dl}$ & $(290-355)$ \\
\hline $\mathrm{RBC}$ & $306 \times 10^{4} / \mu 1$ & $\mathrm{Cl}$ & $106 \mathrm{mEq} / \mathrm{l}$ & Ferritin & $119 \mathrm{ng} / \mathrm{ml}$ & $(3-116)$ \\
\hline $\mathrm{Hb}$ & $9.1 \mathrm{~g} / \mathrm{dl}$ & $\mathrm{Ca}$ & $7.8 \mathrm{mg} / \mathrm{dl}$ & & & \\
\hline $\mathrm{Ht}$ & $27.5 \%$ & $\mathrm{Pi}$ & $4.3 \mathrm{mg} / \mathrm{dl}$ & TSH & $162.5 \mu \mathrm{IU} / \mathrm{ml}$ & $(0.5-4.8)$ \\
\hline $\mathrm{MCV}$ & $89.9 \mathrm{fl}$ & & & $\mathrm{T} 3$ & $60 \mathrm{ng} / \mathrm{dl}$ & $(77-135)$ \\
\hline $\mathrm{MCH}$ & $29.9 \mathrm{pg}$ & BUN & $21 \mathrm{mg} / \mathrm{dl}$ & $\mathrm{T} 4$ & $4.9 \mu \mathrm{g} / \mathrm{dl}$ & $(5.7-10.4)$ \\
\hline \multirow[t]{2}{*}{ Plt } & $26.3 \times 10^{4} / \mu \mathrm{l}$ & Creatinine & $0.9 \mathrm{mg} / \mathrm{dl}$ & $\mathrm{Tg}$ & $>1,000 \mathrm{ng} / \mathrm{ml}$ & \\
\hline & & $\mathrm{TP}$ & $6.4 \mathrm{~g} / \mathrm{dl}$ & TGHA & $<10$ & \\
\hline \multirow[t]{2}{*}{ CRP } & $2.2 \mathrm{mg} / \mathrm{dl}$ & Albumin & $3.4 \mathrm{~g} / \mathrm{dl}$ & MCHA & 80 & \\
\hline & & T.Bil & $1.5 \mathrm{mg} / \mathrm{dl}$ & $\mathrm{Ca}^{2+}$ & $2.04 \mathrm{mEq} / \mathrm{l}$ & \\
\hline \multicolumn{2}{|c|}{ Urinalysis } & AST & $38 \mathrm{IU} / l$ & PTH-C terminal & $0.3 \mathrm{ng} / \mathrm{ml}$ & $(<0.6)$ \\
\hline Glucose & $(-)$ & ALT & $30 \mathrm{IU} / 1$ & $1 \alpha-25(\mathrm{OH})_{2} \mathrm{VD}$ & $25 \mathrm{pg} / \mathrm{ml}$ & $(27.5-68.7)$ \\
\hline Protein & $(-)$ & Alp & $187 \mathrm{IU} / l$ & Calcitonin & $20 \mathrm{pg} / \mathrm{ml}$ & $(15-86)$ \\
\hline \multirow[t]{2}{*}{ Blood } & $( \pm)$ & Amy & $188 \mathrm{IU} / l$ & & & \\
\hline & & $\mathrm{LDH}$ & $405 \mathrm{IU} / \mathrm{l}$ & \multicolumn{2}{|l|}{ Tumor markers } & \\
\hline \multicolumn{2}{|c|}{ Biochemical data } & & & SCC & $0.8 \mathrm{ng} / \mathrm{ml}$ & \\
\hline BS & $77 \mathrm{mg} / \mathrm{dl}$ & & & NSE & $34 \mathrm{ng} / \mathrm{ml}$ & $(<10)$ \\
\hline T-cho & $208 \mathrm{mg} / \mathrm{dl}$ & & & CA125 & $59 \mathrm{U} / \mathrm{ml}$ & $(0-35)$ \\
\hline Trig & $85 \mathrm{mg} / \mathrm{dl}$ & & & & & \\
\hline
\end{tabular}

Tg: thyroglobulin, TGPA: anti-thyroglobulin particle agglutination, MCPA: anti-thyroid microsomal particle agglutination, SCC: squamous cell carcinoma-related antigen, NSE: neuron-specific enolase, CA125: carbohydrate antigen 125. *Numbers in parentheses indicate the normal range.

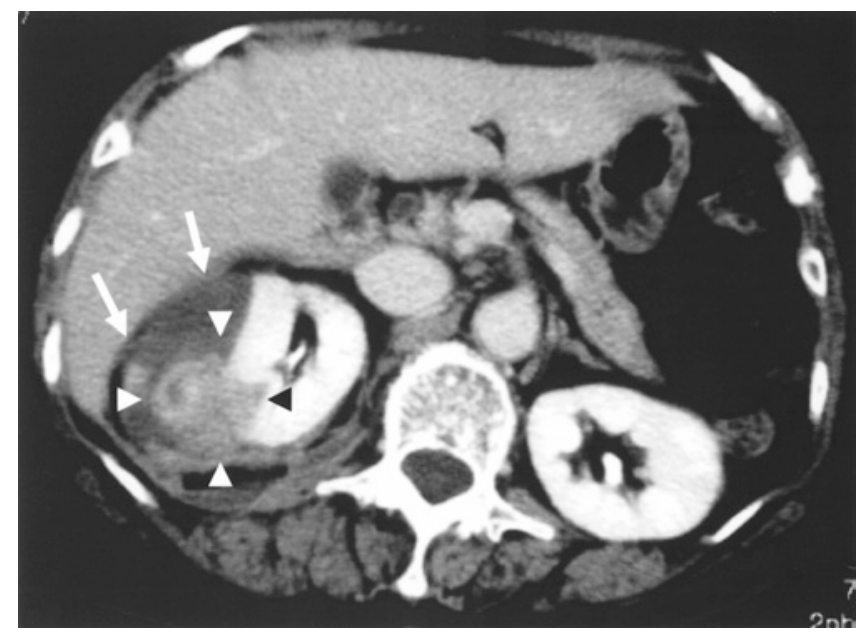

A

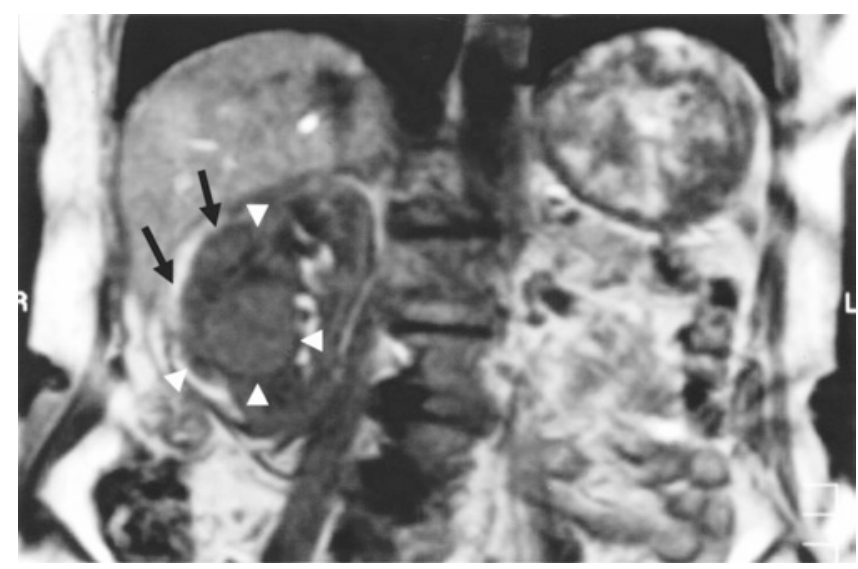

C

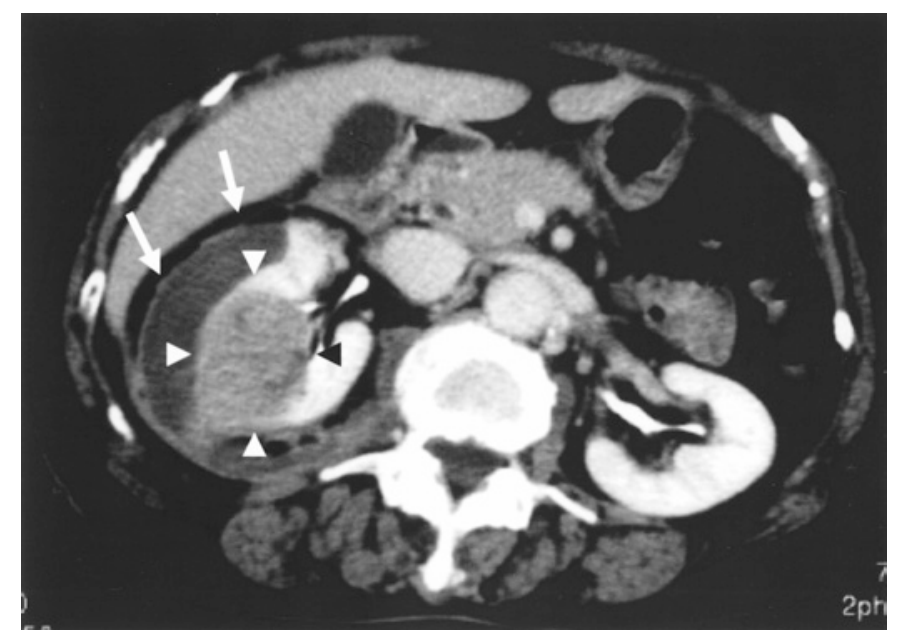

$\mathrm{B}$

Figure 1. Abdominal CT scans and MRI of the renal tumor. Enhanced abdominal CT scans revealed a renal rupture induced by a right renal tumor of $3 \times 3 \mathrm{~cm}$ in diameter $(\mathrm{A}, \mathrm{B})$. The renal tumor (arrowhead) was enhanced and bleeding (arrow) at its periphery. T1-weighted MRI of the abdomen revealed an iso-signal tumor (arrowhead) in the right kidney and high-signal-intensity indicative of bleeding (arrow) in the renal fascia $(\mathbf{C})$. 


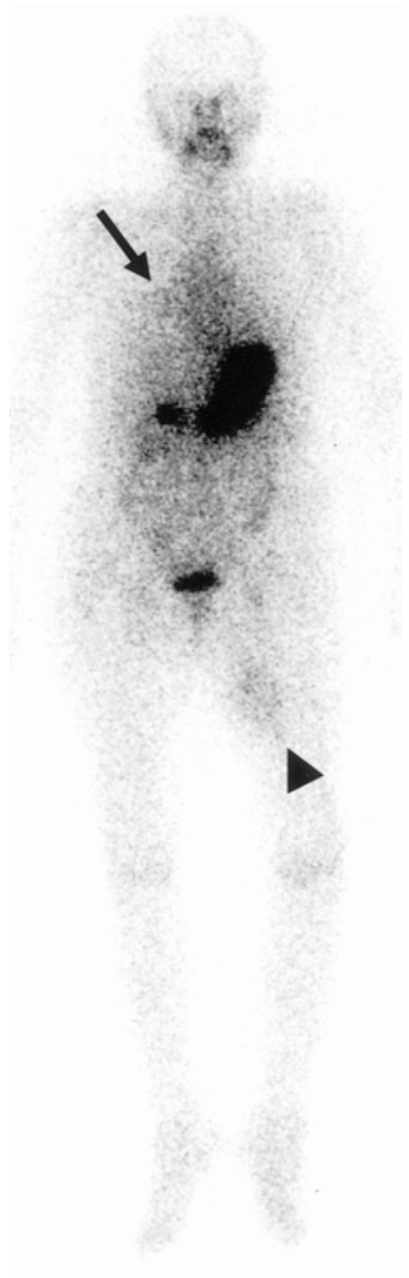

A

B

Figure 2. Whole-body scintigraphy scans of ${ }^{123} \mathrm{I}$ and ${ }^{201} \mathrm{Tl}$. Whole-body scintigraphy scans of ${ }^{123} \mathrm{I}$ (A) and early-phase ${ }^{201} \mathrm{Tl}$ (B) after the nephrectomy revealed strong accumulation in the right lung (arrow) and left thigh (arrowhead).

rate 78 beats/min. No nodules were palpable in her neck. Her heart and lungs were normal. She had right flank abdominal dull pain, but no palpable mass in the abdominal region. A fist-sized immovable mass was palpable in the left thigh. The patient indicated that this mass had gradually enlarged over the previous 6 months.

Laboratory data on admission showed occult blood at urinalyses and normocytic and normochromic anemia, hypothyroidism, and hypocalcemia. Anti-thyroglobulin antibodies were negative and anti-microsomal antibodies were weakly positive. Blood Tg levels were very high (Table 1). We examined the renal tumor with the suspicion that it might have been linked with a recurrent thyroid carcinoma.

Enhanced abdominal computed tomography (CT) scans showed a renal rupture induced by a right renal tumor of $3 \times 3$ $\mathrm{cm}$ in diameter. The renal tumor was enhanced and bleeding was detected on its periphery (Fig. 1A, B). Ten days later after complaining of macrohematuria and right flank pain, T1-weighted magnetic resonance images (MRIs) of the abdomen revealed an iso-signal tumor in the right kidney and a high signal intensity indicative of bleeding in the renal fascia (Fig. 1C). Blood Tg levels (>1,000 ng/ml) remained elevated after a right nephrectomy performed on July 16, 2001, leading us to suspect that the tumors of the lung and thigh muscle were metastases of the thyroid carcinoma. Chest Xray on admission revealed that the tumor on the right lower lung field had grown larger than before. Chest CT scans revealed an approximately $5 \mathrm{~cm}$-wide tumor with a regular margin on the right lung field $\left(\mathrm{S}_{45}\right)$, apparently bound to the rib. Vessels were caught in the tumor and no lymph node was swollen in the mediastinum. T2-weighted MRI demonstrated a high signal intensity mass of $9 \times 9 \mathrm{~cm}$ in diameter in the left thigh muscle. Whole-body scintigraphy scans with ${ }^{123} \mathrm{I}$ (Fig. 2A) and early-phase ${ }^{201} \mathrm{Tl}$ (Fig. 2B) revealed strong accumulation in the tumors of the right lung and left thigh. Whole-body ${ }^{67} \mathrm{Ga}$ scintigraphy scans taken after the right nephrectomy, also showed strong accumulation in the tumors of the right lung and left thigh. The patient chose not to undergo TBLB for the lung tumor, but she consented to a biopsy for the tumor of the thigh muscle on August 28, 2001. The pathological findings of the tumors of the right kidney (Fig. 3C) and left thigh muscle (Fig. 3D) were similar to those of the thyroid carcinoma resected on January 9, 1989 (Fig. 3A, B). The tumor tissue formed a poorly differentiated follicular thyroid carcinoma composed of solid and restiform structures partially containing with relatively small nuclei abundant in chromatin. The carcinoma cells were found to be infiltrating the capsule and vessels on the thyroid tissue (Fig. $3 \mathrm{~A})$. The tumors of the thyroid, kidney, and thigh muscle were positively stained by the Tg-antibody. We undertook an immunohistochemical staining of p53 using a $\times 100$ dilution of mouse p53 monoclonal antibody (DO-7, Novocastra Laboratories Ltd., Newcastle upon Tyne, U.K.). Pathological findings indicated positive staining of the species of the resected tumors of the thyroid and right kidney by p53antibody. We diagnosed the tumors of the kidney and thigh muscle as thyroid carcinoma metastases on this basis.

Upon resection of the left thigh tumor, we informed the patient of the need to perform isotope therapy for the thyroid carcinoma. However, the patient refused the isotope therapy and requested discharge from our hospital as soon as possible. Several weeks after leaving our hospital she was admitted to another hospital for a cerebral infarction and hemiplegia. After about 6 months she died of pulmonary failure caused by the enlargement of the right lung tumor and pulmonary effusion.

\section{Discussion}

We reported a rare case of a follicular thyroid carcinoma associated with metastases to the thigh muscle and lung and a renal rupture induced by a metastatic tumor 13 years after 


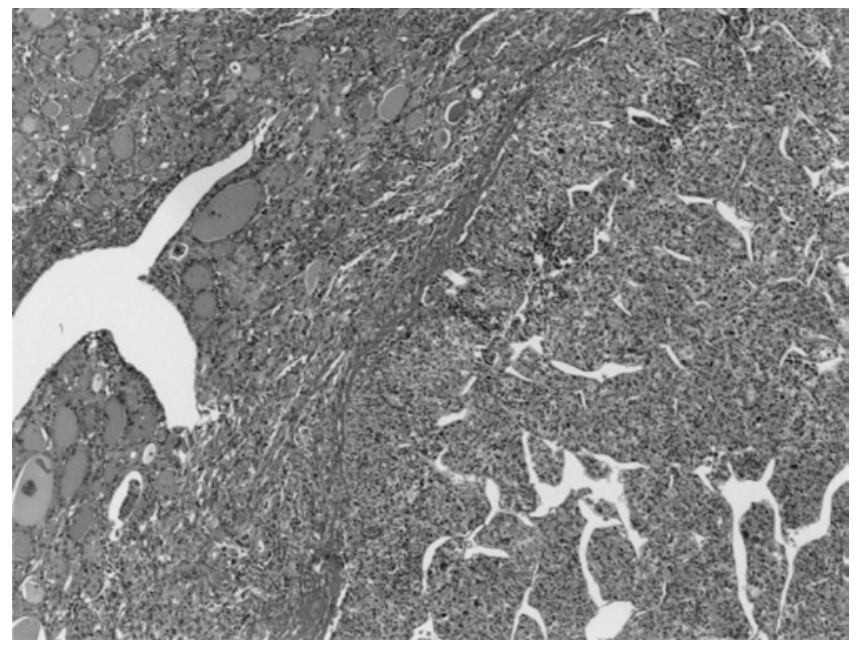

A

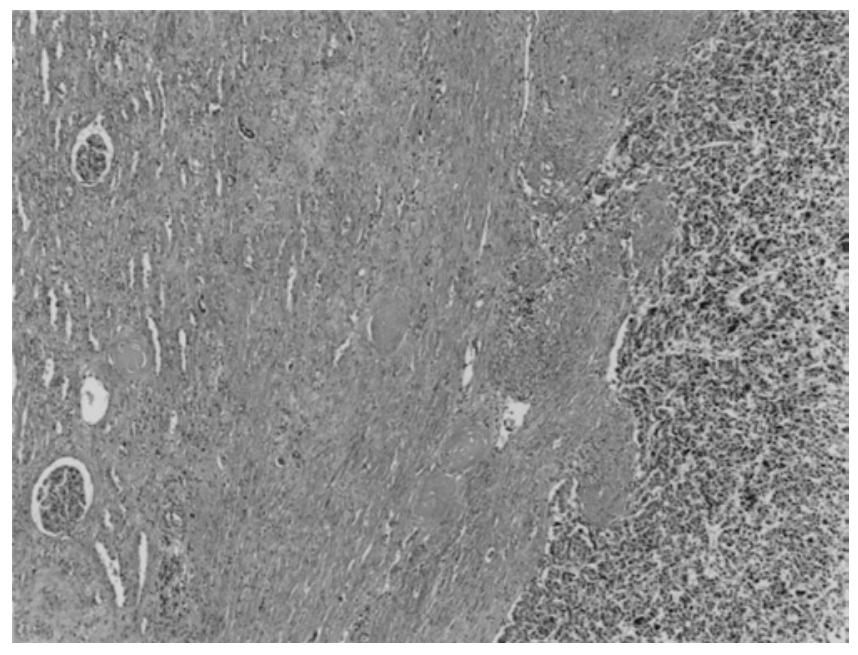

C

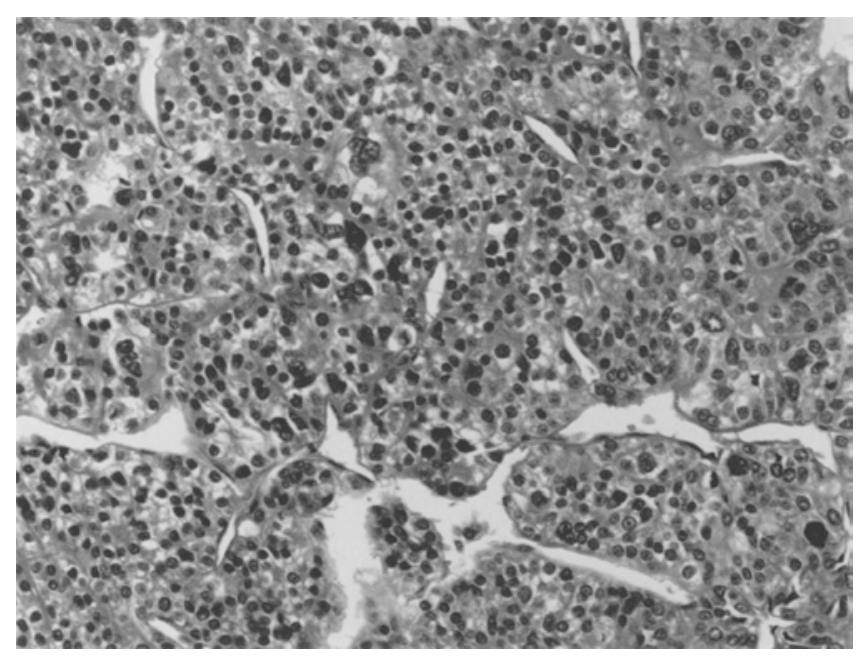

B

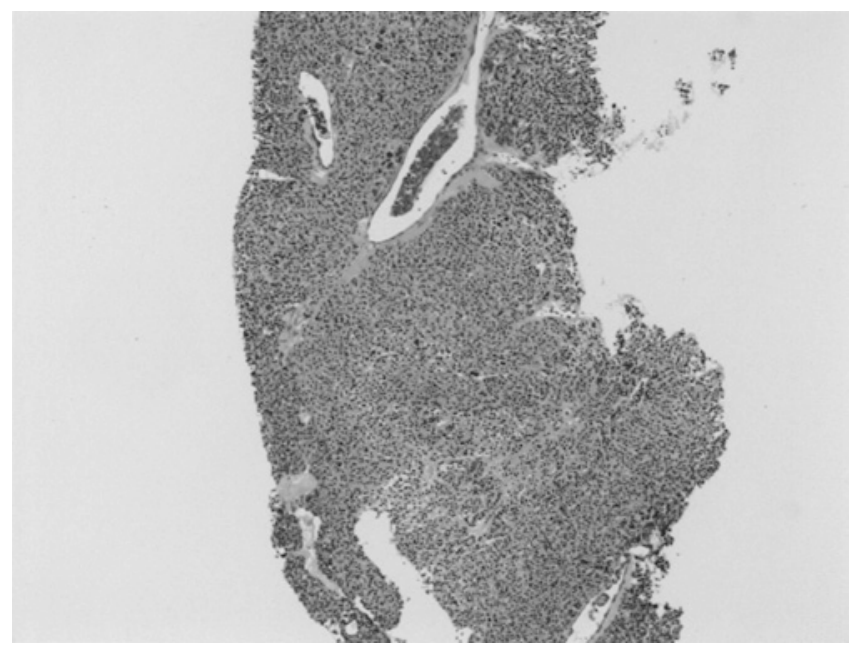

D

Figure 3. Pathology of the tumors of the thyroid, kidney, and thigh. The pathological findings of the tumors of the kidney (C; HE stain, $\times 40)$ and thigh muscle $(D ;$ HE stain, $\times 40)$ were similar to those of the follicular thyroid carcinoma resected on January 9, 1989 (A; HE stain, $\times 40$, B; HE stain, $\times 200$ ). The tumor tissue formed a poorly differentiated follicular thyroid carcinoma composed of a solid- and restiform-structure partially containing relatively small nuclei abundant in chromatin. The carcinoma cells were found to be infiltrating the capsule and vessels of the thyroid tissue (A). The tumors of the thyroid, kidney and thigh muscle were positively stained by the Tg-antibody.

a total thyroidectomy.

The major sites of the distant metastases of thyroid carcinomas are the lungs and bones (2-4). We pathologically diagnosed the tumors at these sites in the present case as thyroid carcinoma metastases. The lung tumor in the present case is likely to be a metastasis of the thyroid carcinoma on scintigraphy, but the patient left our hospital before a definitive diagnosis could be obtained. The diagnosis of thyroid carcinoma metastases remains difficult in spite of the current progress in the diagnostic strategies for thyroid carcinomas by advanced new methods such as aspiration biopsy and reverse transcription-polymerase chain reaction $(\mathrm{ABRP})(5,6)$.
For this reason, we should always be careful to determine whether or not unknown tumors are thyroid carcinoma metastases.

Differentiated thyroid carcinoma recurrence is usually best treated with ${ }^{131} \mathrm{I}(1,7)$. We had planned to administer this therapy in the present case for the major recurrent tumor in the thigh muscle, but the patient declined the therapy and asked to leave the hospital. A subsequent episode, a stroke soon after her discharge, underscored the general difficulty in treating recurrent thyroid carcinomas in the elderly.

Anaplastic thyroid carcinoma rapidly enlarges aggressively, invades the surrounding tissue, and generally has a 


\section{IWAI et al}

very poor prognosis $(1,7-11)$. The pathological findings of the renal tumor in the present case indicated a poorly differentiated follicular thyroid carcinoma rather than an anaplastic carcinoma. However, differentiated thyroid carcinomas are known to cause anaplastic transformation (1215). According to the literature, the frequency of the p53 gene mutation is greater than $20 \%$ in poorly differentiated carcinomas of the thyroid, whereas that in anaplastic carcinoma exceeds $50 \%$ (16). The overexpression of the p53 gene plays a definitive role as a prognostic factor for human thyroid carcinomas $(16,17)$. Given that the present case of poorly differentiated follicular thyroid carcinoma showed overexpression of the p53 gene, the patient probably would have benefited from ${ }^{131}$ I-therapy just after the total thyroidectomy.

We reported a rare case of poorly differentiated follicular thyroid carcinoma metastasized to the thigh muscle, lung, and kidney 13 years after a total thyroidectomy. We recommend that all unknown tumors be considered as potential metastases from thyroid carcinomas.

Acknowledgements: We would like to express our appreciation to Dr. Takao Satou, the Division of Hospital Pathology, Kinki University School of Medicine, for taking the photography of the histology.

\section{References}

1) Schlumberger MJ, Filetti S, Hay ID. Nontoxic goitor and thyroid neoplasia. In: Williams Textbook of Endocrinology, 10th ed., Larsen PR, Kronenberg HM, Melmed S, Polonsky KS, Eds. WB Saunders, Philadelphia, PA, 457-490: 2002.

2) Mazzaferrri EL. Radioiodine and other treatment and outcomes. In: The Thyroid. Braverman LE., Utiger RD, (Eds.), Lippincott Williams \& Wilkins, Philadelphia, PA, USA, 904-929: 2000.

3) Mazzaferrri EL. Thyroid carcinoma: papillary and follicular. In: Endocrine Tumors. Mazzaferri EL., Samaan N, Eds. Blackwell,
Cambridge, England, 1993: 278.

4) Mizukami Y, Michigishi T, Nonomura A, et al. Distant metastases in differentiated thyroid carcinomas: a clinical and pathologic study. Hum Pathol 21: 283-290, 1990.

5) Takano T, Amino N. Cancer-specific mRNAs in thyroid carcinomas: detection, use, and their implication in thyroid carcinogenesis. Endocr J 49: 97-107, 2002.

6) Takano T, Hasegawa Y, Miyauchi A, et al. Quantitative analysis of osteonectin mRNA in thyroid carcinomas. Endocr J 49: 511-516, 2002.

7) Schlumberger MJ, Caillou B. Miscellaneous tumors of the thyroid. In: The Thyroid. Braverman LE., Utiger RD, Eds. Lippincott Williams \& Wilkins, Philadelphia, PA, USA, 944-948: 2000.

8) Obara T. Anaplastic carcinoma. In: A treatment manual for thyroid disease. Takami H, Mori M, Eds. Nankodo, Tokyo, 1998: 95-99.

9) Tsutsui K. Thyroid anaplastic carcinoma: chemotherapy. Naibunpitsu Geka (Endocrine Surg) 16: 37-43, 1999 (in Japanese).

10) Ain KB, Egorin MJ, DeSimone PA. Treatment of anaplastic thyroid carcinoma with paclitaxel: phase 2 trial using ninety-six-hour infusion. Collaborative Anaplastic Thyroid Cancer Health Intervention Trails (CATCHIT) Group. Thyroid 10: 587-594, 2000.

11) Kobayashi $T$, Asakawa $H$, Umeshita $K$, et al. Treatment of 37 patients with anaplastic carcinoma of the thyroid. Head Neck 18: 36-41, 1996.

12) Iwai H, Ohno Y, Aoki N. Thyroid anaplastic carcinoma with humoral hypercalcemia of malignancy (HHM): an autopsy case report. Endocr J 51: 303-310, 2004.

13) Farid NR, Shi Y, Zou M. Molecular basis of thyroid cancer. Endocr Rev 15: 202-232, 1994.

14) Nishiyama RH, Dunn EL, Thompson NW. Anaplastic spindle-cell and giant-cell tumors of the thyroid gland. Cancer 30: 113-127, 1972.

15) Ito $T$, Seyama $T$, Mizuno $T$, et al. Genetic alterations in thyroid tumor progression: association with p53 gene mutations. Jpn J Cancer Res 84: 526-531, 1993.

16) Lam KY, Lo CY, Chan KW, Wan KY. Insular and anaplastic carcinoma of the thyroid. A 45-year comparative study at a single institution and a review of the significance of p53 and p21. Ann Surg 231: 329338, 2000.

17) Dobashi Y, Sakamoto A, Sugimura H, et al. Overexpression of p53 as a possible prognostic factor in human thyroid carcinoma. Am J Surg Pathol 17: 375-381, 1993. 